\title{
Nuevo aCerCamiento a la interacción del Reactivo de Folin-Ciocalteu con azÚCARes duRANTE La CUANTIFICACIÓN DE POLIFENOLES TOTALES
}

\author{
Óscar A. Muñoz-Bernal', Gaspar A. Torres-Aguirre', \\ José A. Núñez-Gastélum', Laura A. de la Rosa ${ }^{1}$, Joaquín Rodrigo-García ${ }^{2}$, \\ J. Fernando Ayala-Zavala ${ }^{3}$ y Emilio Álvarez-Parrilla ${ }^{1 *}$ \\ ${ }^{1}$ Departamento de Ciencias Químico-Biológicas, ${ }^{2}$ Departamento de Ciencias de la Salud, Instituto de Ciencias \\ Biomédicas, Universidad Autónoma de Ciudad Juárez, Av. Plutarco Elías Calles \# 1210, Fovissste Chamizal, \\ C.P. 32310 , Ciudad Juárez, Chihuahua, México. ${ }^{3}$ Centro de Investigación en Alimentación y Desarrollo, A.C. (CIAD, \\ AC), Carretera a la Victoria Km 0.6, La Victoria, C.P. 83000, Hermosillo, Sonora, México. E-mail: ealvarez@uacj.mx*
}

\begin{abstract}
ResUmen
La mezcla de ácidos fosfomolíbdico y fosfotúngstico es el reactivo esencial de uno de los principales métodos para la cuantificación de compuestos polifenólicos en extractos vegetales conocido como método de reactivo de Folin-Ciocalteu (FC). Sin embargo, al igual que otros métodos espectrofotométricos puede ser inespecífico e interaccionar con otras moléculas como azúcares, presentes en los extractos vegetales, que pueden alterar los resultados encontrados. El objetivo del presente trabajo fue determinar el efecto de la glucosa, sacarosa, fructosa, xilosa, manosa, ramnosa y arabinosa sobre la cuantificación de compuestos polifenólicos mediante el método de FC. La fructosa y la xilosa fueron los azúcares con la mayor reactividad, mientras que la sacarosa, ramnosa, manosa y glucosa presentaron el menor efecto. La fructosa y la manosa tanto en las muestras de ácido gálico como en extractos de anís y chile jalapeño así como de especias tradicionales de la cocina mexicana (hoja santa y hoja de aguacate), reaccionaron diferente, ya que la fructosa incrementó la respuesta del método y consecuentemente sobreestimó el contenido de los compuestos polifenólicos y la manosa los subestimó. Los resultados obtenidos muestran que el contenido de azúcar en extractos puede interferir en la estimación de los compuestos polifenólicos, sobre todo si la concentración es muy alta o la fructosa está presente.
\end{abstract}

Palabras Clave: azúcares, enediol, fenoles totales, Folin-Ciocalteu.

\section{New approach to the interaction between Folin-Ciocalteu reactive and sugars during the quantification of total phenols}

\begin{abstract}
Phosphomolybdic and phosphotungstic acids mixture, known as Folin-Ciocalteu reactive, is one of the main methods for the quantification of polyphenolic compounds in vegetable extracts (FC reactive). However, as other spectrophotometric methods, it can be unspecific and interact with other molecules, such as sugars, present in vegetable extracts, modifying the obtained results. The aim of the present study was to evaluate the effect of glucose, sucrose, fructose, xylose, mannose, rhamnose and arabinose on the quantification of polyphenolic compounds by the FC method. Fructose and xylose showed the highest interaction with FC reactive, while sucrose, mannose, rhamnose and glucose showed the lowest effect. Fructose and mannose reacted differently with both gallic acid solutions and anise, jalapeño hot pepper and traditional Mexican spices (hoja santa and avocado leaves). Fructose increased the response of the method, and consequently overestimated the polyphenolic content, while mannose showed an underestimation. The obtained results showed that sugar content in vegetable extracts may interfere on the estimation of polyphenolic content, especially if high content of fructose is present in the samples.
\end{abstract}

Key Words: sugars, enediol, total phenols, Folin-Ciocalteu.

Nota: Artículo recibido el 09 de enero de 2017 y aceptado el 24 de abril de 2017. 


\section{INTRODUCCIÓN}

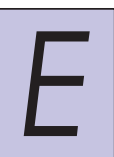

1 ensayo con Folin-Ciocalteu (FC) inicialmente fue empleado para la cuantificación de tirosina en proteínas (Singleton \& Rossi, 1965), pero con el tiempo fue modificado para poder analizar compuestos polifenólicos en distintos tipos de extractos vegetales (Singleton et al., 1999). El reactivo principal del ensayo consiste de una mezcla de ácidos fosfomolíbdico y fosfotúngstico de color amarillo comúnmente denominado "reactivo de FC" y es a partir de la mezcla de ambos ácidos que se producen iones de molibdato y tungsteno. Actualmente se sabe que existe una mayor cantidad de iones de molibdato y éstos funcionan mejor como agentes reductores (Singleton et al., 1999; Huang et al., 2005) La reacción se lleva a cabo en condiciones básicas ( $\mathrm{pH} 10$ ), con la finalidad de que se genere un ion fenolato que reduce al FC mediante una reacción de tipo óxido/reducción (Magalhaes et al., 2010) (Figura 1) y genera la formación de un complejo de $\mathrm{Mo}(\mathrm{V})$ que presenta una coloración azul cuya absorbancia se mide a una longitud de onda de $765 \mathrm{~nm}$ (Chen et al., 2015; Margraf et al., 2015; Everette et al., 2010).

Los extractos de productos vegetales, ya sean acuosos u orgánicos, contienen una gran cantidad de biomoléculas. Se ha estudiado que algunas de estas moléculas de características no polifenólicas pueden interaccionar con el $\mathrm{FC}$, lo que puede repercutir en una sobreestimación. Algunos de los principales compuestos que pueden interferir son: azúcares reductores como fructosa y glucosa, aminoácidos y ácido ascórbico (Granato et al., 2016; Lester et al., 2012; Ludwig et al., 2013; Shanmugavelan et al., 2013).

A pesar de ser un método desarrollado a mediados de los años 60 , no ha sido modificado a través del tiempo y continúa siendo ampliamente aceptado para la cuantificación de compuestos fenólicos en matrices vegetales y sus extractos. Sin embargo, diversos estudios presentan resultados contradictorios en cuanto al efecto de los azúcares sobre la cuantificación de compuestos polifenólicos. O' Sullivan \& Mathison (1970) observaron un efecto diferencial de diversos azúcares con el FC al cuantificar tirosina y proteínas. Así, la fructosa a una concentración de $10 \mathrm{mM}$ mostraba un efecto elevado de sobreestimación, en cambio en la xilosa y ramnosa fue menor y no significativo para la glucosa y manosa con el FC. En otro estudio, Slinkard \& Singleton, 1977, demostraron que existe el efecto de sobreestimación, especialmente cuando se realiza una incubación de $55^{\circ} \mathrm{C}$ en las muestras donde se encuentra la fructosa y la glucosa, en comparación con la incubación a temperatura ambiente, proponiendo factores de corrección para este efecto. Singleton et al., 1999 mencionan que la fructosa no presenta grupos hidroxilos que puedan interaccionar con el reactivo, sin embargo, citan que puede ocasionar una sobreestimación y que debe utilizarse un factor de corrección. Así mismo, Everette et al., 2010 reportaron que la fructosa y la glucosa no presentan reacción con FC a una concentración de $127 \mathrm{mM}$. Estos resultados muestran que existe una controversia sobre las interacciones de los azúcares con el reactivo de FC y su efecto sobre la cuantificación de compuestos polifenólicos en muestras de origen vegetal. Por consiguiente, el objetivo de este estudio fue determinar la reactividad de diferentes azúcares reductores y no reductores con FC bajo distintos tiempos y temperaturas de incubación. Así, como determinar tanto el efecto de los azúcares con el ácido gálico como el de su presencia simultánea en compuestos polifenólicos de extractos de matrices vegetales.

\section{Materiales y Métodos}

Todos los reactivos utilizados fueron adquiridos de SigmaAldrich (St. Louis, MO, USA). Para realizar las curvas de calibración se utilizó ácido gálico. Los azúcares analizados, fueron D-glucosa, D-fructosa, sacarosa, D-manosa, D-xilosa, D-arabinosa y D-ramnosa. Para el ensayo con FC se utilizaron carbonato de sodio y Folin-Ciocalteu $2 \mathrm{~N}$.

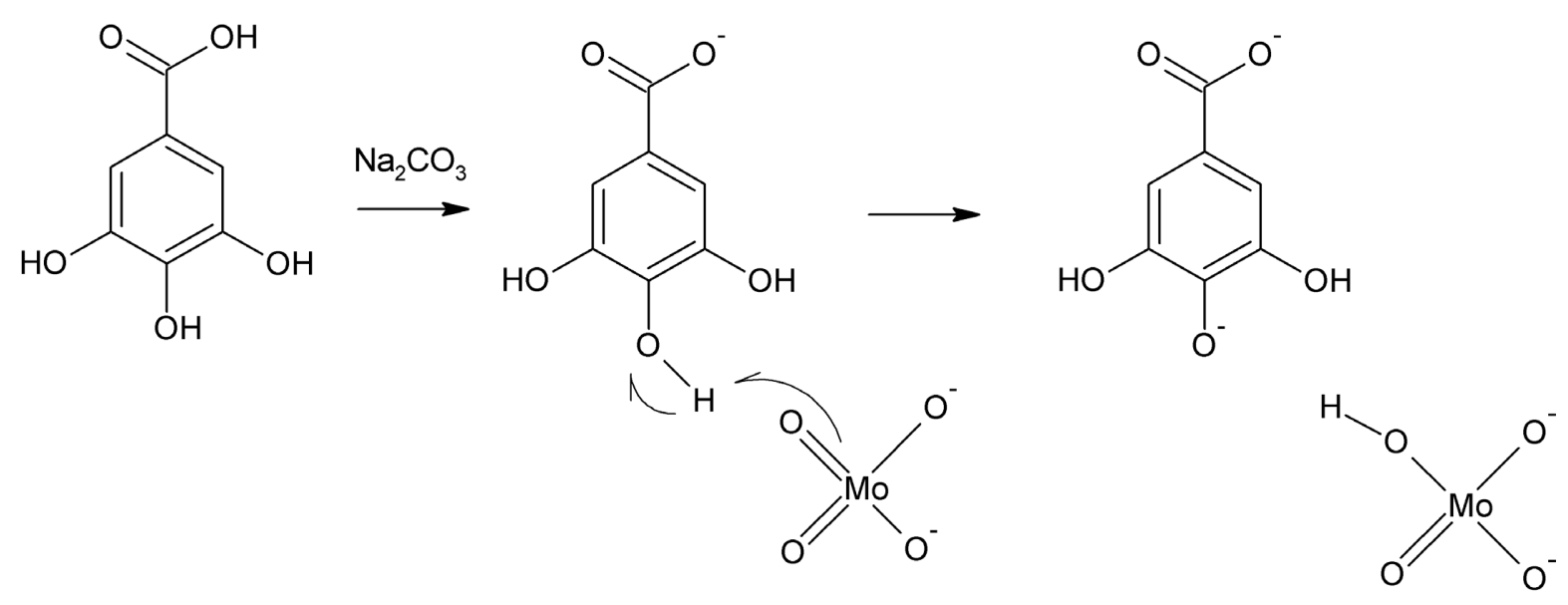

Figura 1. Reacción entre el ácido gálico y el reactivo de FC. 


\section{Determinación de fenoles totales con Folin-Ciocalteu}

El ensayo con Folin-Ciocalteu se realizó de acuerdo al método descrito por Moreno-Escamilla et al., 2015, con ligeras modificaciones. Brevemente, se prepararon disoluciones acuosas de ácido gálico de 1.12 a $0.07 \mathrm{mM}$ y de cada uno de los azúcares de 500 a $31 \mathrm{mM}$. A $250 \mu \mathrm{L}$ de ácido gálico y de azúcar se le agregó $1 \mathrm{~mL}$ de carbonato de sodio $(7.5 \%$ en agua destilada). Posteriormente se añadieron $1,250 \mu \mathrm{L}$ de FC preparado al momento (10\% en agua destilada). Las mezclas fueron incubadas por $15 \mathrm{~min}$ a $50^{\circ} \mathrm{C}$ a baño María y al terminar el proceso fueron colocadas en un baño de agua fría para detener la reacción. Trecientos $\mu \mathrm{L}$ fueron colocados por triplicado en una microplaca y se monitoreó la absorbancia utilizando un espectrofotómetro de microplaca (BioRad, xMark) a una longitud de onda de $760 \mathrm{~nm}$. Para comparar el efecto de las condiciones de incubación en la reacción, se siguió el mismo procedimiento, incubando las muestras a temperatura ambiente durante $1 \mathrm{~h}$. Los resultados se expresan como porcentaje de reacción (\% Reacción), tomando como el 100\% la absorbancia del punto más alto de la curva del ácido gálico.

\section{Determinación de la reacción de los azúcares con Folin- Ciocalteu}

Para evaluar la reacción de los azúcares y determinar la concentración de compuestos polifenólicos en ellos con FC, en un primer experimento, se prepararon disoluciones de fructosa y manosa a diferentes concentraciones (azúcares de mayor y menor reactividad en el ensayo anterior) primero de 500 a $31 \mathrm{mM}$, disueltas en ácido gálico a $0.6 \mathrm{mM}$. En un segundo experimento se prepararon disoluciones de ácido gálico de 1.12 a $0.07 \mathrm{mM}$ en fructosa y manosa a $500 \mathrm{mM}$.

Por último, se vio el efecto que tienen los azúcares en los extractos de vegetales que presentan bajas concentraciones de azúcar (anís, chile jalapeño, hoja santa y hoja de aguacate), determinando los compuestos polifenólicos en presencia y ausencia de azúcares. Los vegetales fueron adquiridos en un supermercado de Ciudad Juárez y se obtuvieron extractos metanólicos (80\%), de acuerdo a la metodología propuesta por Moreno-Escamilla et al., 2015, con ligeras modificaciones. A continuación se pesaron $10 \mathrm{mg}$ de cada extracto vegetal que se disolvieron en $10 \mathrm{~mL}$ de agua y en disoluciones de fructosa y manosa a $500 \mathrm{mM}$, además una mezcla de manosa y fructosa cada una a $250 \mathrm{mM}$. Los resultados fueron expresados como milimoles equivalentes de ácido gálico por cada gramo de extracto (mmoles EAG/g extracto) determinados con la ecuación de la recta de calibrado de ácido gálico.

\section{Análisis estadístico}

Se realizó un análisis de varianza de una sola vía (ANOVA), para determinar el impacto sobre las concentraciones de compuestos polifenólicos de los extractos de vegetales con y sin presencia de azúcares. Para ello se utilizó el programa SPSS versión 23. Cuando el ANOVA mostró diferencias significativas, se realizó un análisis de comparación de medias (Tukey post hoc).

\section{RESULTADOS Y DISCUSIÓN}

Debido a que en la bibliografía existen diferentes condiciones experimentales para la determinación de compuestos polifenólicos mediante el reactivo FC, inicialmente se evaluó el efecto de la temperatura de reacción. Para ello se realizaron ensayos con $\mathrm{FC} \mathrm{a} 50{ }^{\circ} \mathrm{C}$ por 15 min y a temperatura ambiente durante $1 \mathrm{~h}$. El efecto de la temperatura en la reacción de FC se muestra en la Figura 2. En la Figura 2A se observa la reacción de $\mathrm{FC}$ con una incubación a $50{ }^{\circ} \mathrm{C}$ por $15 \mathrm{~min}$, mientras que en la Figura 2B se muestra la reacción con incubación a temperatura ambiente por $1 \mathrm{~h}$. Se puede apreciar que los azúcares con mayor

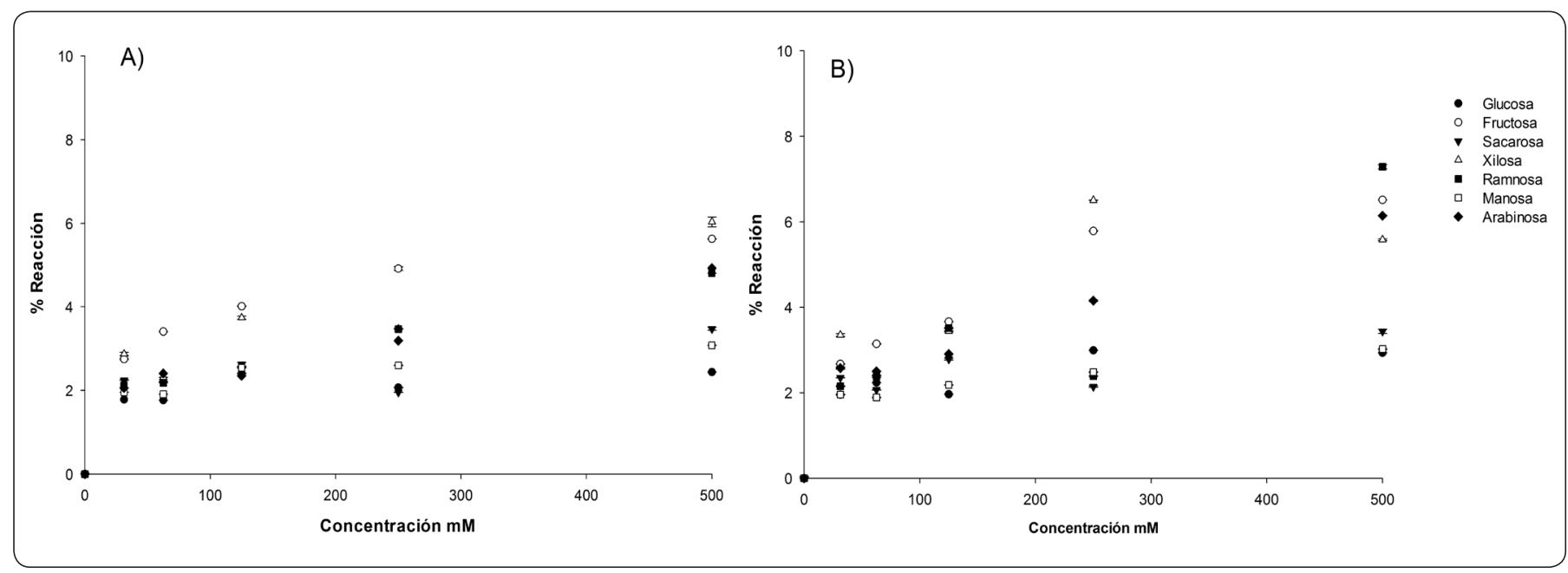

Figura 2. Reacción de los azúcares con el reactivo de FC. A) Reacción a $50{ }^{\circ} \mathrm{C}$ durante 15 min. B) Reacción a temperatura ambiente durante $1 \mathrm{~h}$. 
interferencia son la fructosa y la xilosa en ambas pruebas, mientras que la glucosa, manosa, ramnosa y sacarosa son los azúcares que presentan el menor porcentaje de reactividad en las dos temperaturas de incubación. Los porcentajes de reacción en ambos tratamientos fueron muy similares, existiendo mayor variabilidad en los resultados cuando la incubación se llevó a temperatura ambiente. Al comparar los resultados de la Figura 2Ay 2B, muestran que los azúcares estudiados no presentan una reactividad diferente al ser expuestos a una temperatura elevada o al ser incubados a temperatura ambiente. En función de estos resultados se decidió desarrollar el resto de los experimentos a $50{ }^{\circ} \mathrm{C}$ durante $15 \mathrm{~min}$. También se observa que la reactividad de los azúcares con FC se incrementa conforme aumenta su concentración. Singleton et al., 1999 reportaron que los azúcares a $138 \mathrm{mM}$ no presentaron reacción con FC cuando la incubación se llevó a cabo a temperatura ambiente y que el efecto de los azúcares se hizo evidente cuando las concentraciones fueron mayores. Esto concuerda con los resultados obtenidos, en donde a mayor concentración de azúcares existe un mayor porcentaje de reactividad. Everette et al., 2010, evaluaron el efecto de varios compuestos que pueden reaccionar con $\mathrm{FC}$, entre los que se encuentran azúcares (fructosa, sacarosa, glucosa), proteínas y aminoácidos (alanina, arginina, albumina), vitaminas (ácido ascórbico, biotina, ácido fólico), sales inorgánicas (nitrito de sodio, sulfito de sodio, ioduro de potasio), bases nucleicas (adenina, guanina, citosina), ácidos grasos insaturados (ácido araquidónico, ácido linoleico, ácido linolénico) y complejos metálicos. Los autores reportaron que a una concentración de $27 \mathrm{mM}$ de glucosa y fructosa no hubo efecto sobre la respuesta de FC. Sin embargo, nuestros resultados muestran que ambos azúcares reaccionan con $\mathrm{FC}$ a concentraciones de 31 a 500 $\mathrm{mM}$, lo cual parece indicar que la respuesta depende de la concentración. Estos resultados concuerdan con lo realizado por Singleton et al., 1999, que al comparar el efecto de los azúcares utilizando $\mathrm{FC}$, encontraron que la fructosa tuvo un efecto mayor en comparación con la glucosa debido a la concentración.

Una vez determinado, que la presencia de azúcares puede modificar la respuesta de FC, se decidió evaluar el efecto de dos de ellos: uno con un efecto importante (fructosa) y otro con un efecto ligero (manosa), ambos a una concentración de $500 \mathrm{mM}$ sobre la curva de calibración del ácido gálico. En la Figura 3 se observa que tanto la fructosa como la manosa, incrementan la respuesta del FC, siendo la fructosa el azúcar que presentó el mayor impacto sobre la determinación de compuestos polifenólicos, lo cual se ve reflejado en una mayor pendiente en la curva de calibración. El efecto de los azúcares con FC es explicado por las condiciones básicas en que se realizó el ensayo, lo que ocasionó que los monosacáridos se degradaran generando enedioles, para actuar como agentes reductores, incrementando la respuesta del análisis de compuestos polifenólicos por el método de FC en muestras con concentraciones altas en azúcares (Sánchez-Rangel et al., 2013).
En la Figura 4A se ve el efecto de la combinación de fructosa con ácido gálico a una concentración de $0.56 \mathrm{mM}$. En esta figura se observa que la absorbancia de FC con concentraciones crecientes de fructosa, no presentó un cambio evidente en la pendiente $(\mathrm{m}=0.0002)$ igual a lo reportado por Singleton et al., 1999 para este mismo azúcar. Sin embargo, cuando se lee la absorbancia de una muestra de fructosa mezclada con el ácido gálico $(0.65 \mathrm{mM})$, hay un aumento de la absorbancia dependiente de la concentración de fructosa $(\mathrm{m}=0.0009)$. Al comparar la absorbancia de la combinación de ácido gálico y azúcar con la del ácido gálico solo, se nota al inicio un aumento que puede corresponder a la suma de la absorbancia de la fructosa sola y el ácido gálico solo. Sin embargo, en las concentraciones más altas de fructosa, el aumento en la absorbancia no corresponde a la suma de los dos compuestos, sino posiblemente a un efecto sinérgico entre ellos dos cuando están combinados en el mismo medio. Este resultado indica que puede existir un efecto de sobreestimación en la cuantificación de compuestos polifenólicos cuando la fructosa está presente en la muestra. A diferencia de la fructosa, en el caso de la manosa (Figura 4B), no se vio el efecto sinérgico con el ácido gálico. De manera interesante, a concentraciones bajas de manosa parece haber un efecto antagónico entre la interacción del ácido gálico y el azúcar con una absorbancia menor que la del ácido gálico solo. Sin embargo, al aumentar la concentración de manosa este efecto antagónico parece reducirse y la absorbancia es ligeramente mayor a la del ácido gálico solo.

Con la finalidad de evaluar el efecto que puede tener la presencia de azúcares sobre la cuantificación de compuestos polifenólicos, se realizó el ensayo con FC a cuatro extractos que no poseen azúcares, en presencia y ausencia de fructosa, manosa y una mezcla de ambas. En la Tabla I se presentan los resultados de estas pruebas.

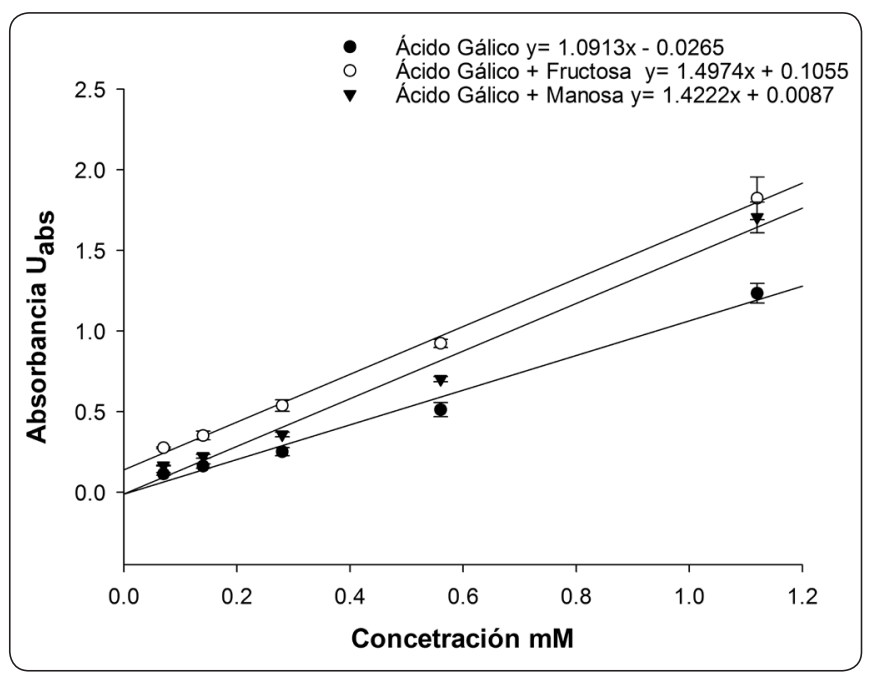

Figura 3. Curvas de ácido gálico con fructosa y manosa $500 \mathrm{mM}$. 
En la Tabla I se ve que la adición de fructosa aumenta significativamente la cuantificación de compuestos polifenólicos por el método de FC para los extractos de anís, hoja santa y hoja de aguacate. En el caso de la manosa, en concordancia con los resultados de la Figura 4, tuvo un efecto menor que la fructosa sobre el valor de compuestos polifenólicos, siendo significativo, respecto al control (ausencia de azúcar) solamente para el anís. Cuando la fructosa y la manosa están presentes en el extracto, parece que el resultado es la combinación del efecto de ambas y el incremento en el valor obtenido es intermedio entre ellas. El chile jalapeño muestra un comportamiento diferente a los otros extractos, ya que la fructosa no presentó un incremento en el valor de FC, mientras que la presencia de manosa y la combinación de ambos azúcares resultó además de una reducción en el valor de compuestos polifenólicos, un efecto de subestimación en éstos debido a que el chile jalapeño contiene una gran cantidad de ácido ascórbico y clorofilas, que pueden interactuar con el reactivo de FC al modificar la cuantificación de fenoles totales en la muestra (Sánchez-Rangel et al., 2013; Deepa et al., 2007; Bae et al., 2014; Georgé et al., 2005), lo que podría explicar el comportamiento atípico que presenta el chile jalapeño cuando está presente un azúcar o la combinación de ambos.

\section{Conclusiones}

Los resultados son diversos porque muestran que la glucosa, sacarosa, ramnosa, arabinosa, manosa y xilosa presentaron una reactividad mínima con FC. A diferencia de la fructosa que presentó una elevada reactividad. No se observaron cambios significativos en la respuesta de FC en presencia de los azúcares a temperatura ambiente o con incubación a $50{ }^{\circ} \mathrm{C}$, produciendo la presencia de fructosa un efecto sinérgico con el ácido gálico al reaccionar con $\mathrm{FC}$ que se refleja en un aumento de la señal. Por último, la presencia de azúcares en extractos vegetales puede interferir en la respuesta del reactivo de FC. Así, al

\begin{tabular}{|c|c|c|c|c|}
\hline \multirow[b]{2}{*}{ Muestra } & \multicolumn{4}{|c|}{ mmol EAG/g extracto } \\
\hline & Control & Fructosa & Manosa & $\mathbf{F}+\mathbf{M}$ \\
\hline Anís & $\begin{array}{c}0.36 \pm \\
0.00^{\mathrm{c}}\end{array}$ & $0.60 \pm 0.01^{\mathrm{a}}$ & $\begin{array}{c}0.44 \pm \\
0.01^{\mathrm{b}}\end{array}$ & $\begin{array}{c}0.48 \pm \\
0.05^{\mathrm{b}}\end{array}$ \\
\hline $\begin{array}{l}\text { Chile } \\
\text { jalapeño }\end{array}$ & $\begin{array}{c}0.41 \pm \\
0.01^{\mathrm{a}}\end{array}$ & $0.42 \pm 0.01^{\mathrm{a}}$ & $\begin{array}{c}0.23 \pm \\
0.01^{\mathrm{c}}\end{array}$ & $\begin{array}{c}0.33 \pm \\
0.04^{\mathrm{b}}\end{array}$ \\
\hline Hoja santa & $\begin{array}{c}0.63 \pm \\
0.01^{\mathrm{c}}\end{array}$ & $0.93 \pm 0.00^{\mathrm{a}}$ & $\begin{array}{l}0.65 \pm \\
0.01^{\mathrm{bc}}\end{array}$ & $\begin{array}{c}0.73 \pm \\
0.07^{\mathrm{b}}\end{array}$ \\
\hline $\begin{array}{l}\text { Hoja de } \\
\text { aguacate }\end{array}$ & $\begin{array}{c}1.38 \pm \\
0.03^{\mathrm{c}}\end{array}$ & $2.07 \pm 0.05^{\mathrm{a}}$ & $\begin{array}{c}1.38 \pm \\
0.05^{\mathrm{c}}\end{array}$ & $\begin{array}{c}1.81 \pm \\
0.05^{\mathrm{b}}\end{array}$ \\
\hline $\begin{array}{l}\text { *Las letras } \\
\text { extracto en }\end{array}$ & difer & $\begin{array}{l}\text { significativa } \\
\text { de azúcares. }\end{array}$ & $\mathrm{p}=0.0$ & el mismo \\
\hline
\end{tabular}

Tabla I. Concentración en milimoles equivalentes de ácido gálico (mmol EAG/ g extracto) de los extractos solos y con la adición de azúcares a $500 \mathrm{mM}$ y la combinación de $\mathrm{F}+\mathrm{M}$ 125 mM cada una para una concentración final de 500 mM.

tener concentraciones elevadas de fructosa se sobreestimó la cuantificación de compuestos polifenólicos en los vegetales evaluados, mientras que la manosa subestimó la cuantificación de estos compuestos. Lo anterior ratifica la importancia de tomar en cuenta la presencia de azúcares en los extractos de material vegetal que se están analizando y en caso necesario (por ejemplo frutas), eliminar estos azúcares, por ejemplo mediante una extracción de fase sólida (C-18), previo a la determinación de compuestos polifenólicos mediante el uso de FC.

\section{Agradecimientos}

Los autores agradecen a CONACYT(CB-2011-01-167932, CB2011-01-167164) por el financiamiento económico y también por las becas otorgadas a Óscar A. Muñoz Bernal y Gaspar A. Torres Aguirre, para realizar sus estudios de Maestría en Ciencias Químico Biológicas.

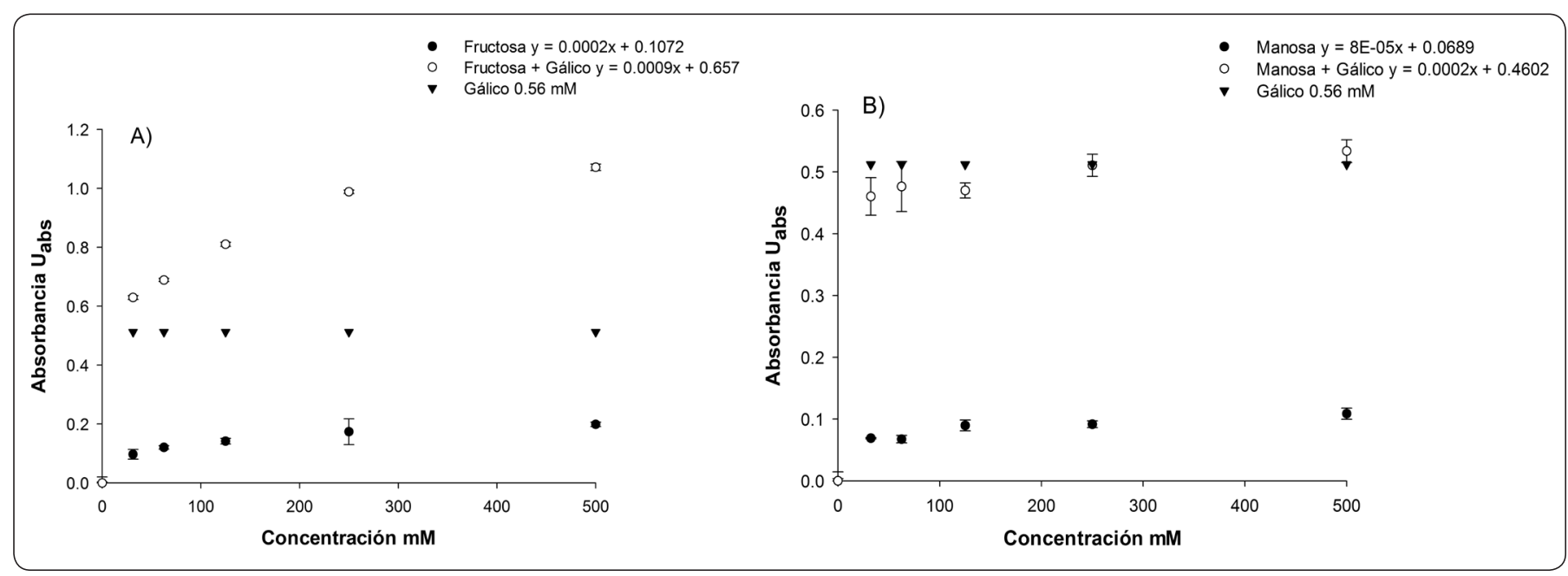

Figura 4. A) Cambios en la absorbancia de la fructosa y fructosa con ácido gálico a $0.56 \mathrm{mM}$. B) Cambios en la absorbancia de la manosa y manosa con ácido gálico $0.56 \mathrm{mM}$. 


\section{Referencias}

Bae, H., Jayaprakasha, G. K.,Crosby, K., Yoo, K. S., Leskovar, D. I., Jifon, J. \& Patil, B. S. (2014). Ascorbic acid, capsaicinoid, and flavonoid aglycone concentrations as a function of fruit maturity stage in greenhouse-grown peppers. Journal of Food Composition and Analysis 33, 195-202. DOI 10.1016/j.jfca.2013.11.009.

Chen, L. Y., Cheng, C. W. \& Liang, J. Y. (2015). Effect of esterification condensation on the Folin-Ciocalteu method for the quantitative measurement of total phenols. Food Chem. 170, 10-50. DOI.10.1016/j.foodchem.2014.08.038.

Deepa, N., Kaur, C., George, B., Singh, B. \& Kapoor, H. C. (2007). Antioxidant constituents in some sweet pepper (Capsicum annuum L.) genotypes during maturity. LWT-Food Science and Technology 40, 121-129. DOI 10.1016/j.lwt.2005.09.016.

Everette, J. D., Bryant, Q. M., Green, A. M., Abbey, Y. A., Wangila, G. W. \& Walker, R. B. (2010). Thorough study of reactivity of various compound classes toward the Folin-Ciocalteu reagent. J. Agric. Food Chem. 58, 8139-8144. DOI 10.1021/jf1005935.

Georgé, S., Brat, P., Alter, P. \& Amiot, M. (2005). Rapid Determination of Polyphenols and Vitamin C in Plant- Derived Products. J. Agric. Food Chem. 53, 1370-1373.

Granato, D., Santos, J. S., Maciel, L. G. \& Nunes, D. S. (2016). Chemical perspective and criticism on selected analytical methods used to estimate the total content of phenolic compounds in food matrices. TrAC Trends in Analytical Chemistry, 80, 266-279. DOI 10.1016/j.trac.2016.03.010.

Huang, D., Ou, B. \& Prior, R. (2005). The Chemistry behind Antioxidant Capacity Assays. J. Agric. Food Chem. 53, 1841-1856. DOI: 10.1021/jf030723c

Lester, G. E., Lewers, K. S., Medina, M. B. \& Saftner, R. A. (2012). Comparative analysis of strawberry total phenolics via Fast Blue BB vs. Folin-Ciocalteu: Assay interference by ascorbic acid. Journal of Food Composition and Analysis 27, 102-107. DOI 10.1016/j.jfca.2012.05.003.

Ludwig, I. A., Bravo, J., De Peña, M. P. \& Cid, C. (2013). Effect of sugar addition (torrefacto) during roasting process on antioxidant capacity and phenolics of coffee. LWT - Food Science and Technology 51 , 553-559. DOI 10.1016/j.lwt.2012.12.010.

Magalhaes, L. M., Santos, F., Segundo, M. A., Reis, S. \& Lima, J.
L. (2010) Rapid microplate high-throughput methodology for assessment of Folin-Ciocalteu reducing capacity. Talanta $\mathbf{8 3}$, 441-447. DOI 10.1016/j.talanta.2010.09.042.

Margraf, T., Karnopp, A. R., Rosso, N. D. \& Granato, D. (2015) Comparison between Folin-Ciocalteu and Prussian Blue Assays to Estimate The Total Phenolic Content of Juices and Teas Using 96-Well Microplates. J. Food Sci. 80, C2397-403. DOI 10.1111/1750-3841.13077.

Moreno-Escamilla, J. O., De La Rosa, L. A., López-Díaz, J. A., Rodrigo-García, J., Núñez-Gastélum, J. A. \& Álvarez-Parrilla, E. (2015). Effect of the smoking process and firewood type in the phytochemical content and antioxidant capacity of red Jalapeño pepper during its transformation to chipotle pepper. Food Research International 76, 654-660. DOI 10.1016/j. foodres.2015.07.031.

O'Sullivan, J. \& Mathison, G. E. (1970). Interference by monosaccharides with the estimation of tyrosine and proteins using the Folin-Ciocalteu phenol reagent. Analytical Biochemistry 35, 540-542. DOI 10.1016/0003-2697(70)90221-6

Sánchez-Rangel, J. C., Benavides, J., Heredia, J. B., Cisneros-Zevallos, L. \& Jacobo-Velázquez, D. A. (2013). The Folin-Ciocalteu assay revisited: improvement of its specificity for total phenolic content determination. Analytical Methods 5, 5990-5999. DOI 10.1039/ C3AY41125G.

Shanmugavelan, P., Kim, S. Y., Kim, J. B., Kim, H. W., Cho, S. M., Kim, S. N., Kim, S. Y., Cho, Y. S. \& Kim, H. R. (2013). Evaluation of sugar content and composition in commonly consumed Korean vegetables, fruits, cereals, seed plants, and leaves by HPLC-ELSD. CarbohydrRes. 380, 112-117. DOI 10.1016/j.carres.2013.06.024.

Singleton, V. \& Rossi, J. A. (1965). Colorimetry of Total Phenolics With Phosphomolybdic-Phosphotungstic Acid Reagents. Am. J. Enol. Vitic. 16, 144-158.

Singleton, V., Orthofer, R. \& Lamuela-Raventós, R. (1999). Analysis of Total Phenols and Other Oxidation substrates and Antioxidants by Means of Folin-Ciocalteu Reagent. Methods in Enzymology 299, 152-179.

Slinkard, K. \& Singleton, V.(1977). Total Phenol Analysis: Automation and Comparison with Manual Methods. Am. J. Enol. Vitic. 28, $49-56$. 